\title{
The cockayne syndrome B protein is essential for neuronal differentiation and neuritogenesis
}

\author{
F Ciaffardini ${ }^{1}$, S Nicolai ${ }^{1}$, M Caputo', G Canu ${ }^{1}$, E Paccosi ${ }^{1}$, M Costantino ${ }^{1}$, M Frontini ${ }^{2}$, AS Balajee ${ }^{*, 3}$ and L Proietti-De-Santis ${ }^{\star, 1}$
}

Cockayne syndrome (CS) is a progressive developmental and neurodegenerative disorder resulting in premature death at childhood and cells derived from CS patients display DNA repair and transcriptional defects. CS is caused by mutations in csa and $c s b$ genes, and patients with csb mutation are more prevalent. A hallmark feature of CSB patients is neurodegeneration but the precise molecular cause for this defect remains enigmatic. Further, it is not clear whether the neurodegenerative condition is due to loss of CSB-mediated functions in adult neurogenesis. In this study, we examined the role of CSB in neurogenesis by using the human neural progenitor cells that have self-renewal and differentiation capabilities. In this model system, stable CSB knockdown dramatically reduced the differentiation potential of human neural progenitor cells revealing a key role for CSB in neurogenesis. Neurite outgrowth, a characteristic feature of differentiated neurons, was also greatly abolished in CSBsuppressed cells. In corroboration with this, expression of MAP2 (microtubule-associated protein 2), a crucial player in neuritogenesis, was also impaired in CSB-suppressed cells. Consistent with reduced MAP2 expression in CSB-depleted neural cells, tandem affinity purification and chromatin immunoprecipitation studies revealed a potential role for CSB in the assembly of transcription complex on MAP2 promoter. Altogether, our data led us to conclude that CSB has a crucial role in coordinated regulation of transcription and chromatin remodeling activities that are required during neurogenesis.

Cell Death and Disease (2014) 5, e1268; doi:10.1038/cddis.2014.228; published online 29 May 2014

Subject Category: Neuroscience

Cockayne syndrome (CS) is a rare human autosomal recessive disorder. CS patients are characterized by severe photosensivity, growth retardation, cachectic dwarfism, features of premature aging and progressive neurological abnormalities of the central nervous system including microcephaly, cerebellar atrophy and demyelinating peripheral neuropathy. ${ }^{1-3}$

CS patients have been assigned to two complementation groups (CSA and CSB), whose corresponding genes (csa and $c s b)$ have been cloned. ${ }^{4-6}$ CSB protein has critical roles in a subpathway of nucleotide excision repair known as transcription-coupled repair (TCR). ${ }^{7-10}$ TCR removes transcriptionblocking DNA lesions, located on the transcribed strands of active genes and inefficient or lack of TCR triggers an apoptotic signal, which depends more on the functional status of CSB. ${ }^{11,12}$ Besides its involvement in TCR of ultraviolet (UV) damage, CSB has also been implicated in base excision repair and in tumorigenesis. ${ }^{13,14}$

Although a defect in TCR pathway could potentially account for the enhanced photosensitivity of CS patients, other pathological features including neurodegeneration may not be solely explained by TCR defect. ${ }^{15}$ This notion is somewhat strengthened by the demonstrated involvement of CSB in basal transcription mediated by RNA polymerases I and II. ${ }^{16-22}$ More recently, we and others have demonstrated that CSB mediates the transcriptional programs following exposure to cellular stressors such as UV, oxidative damage, inflammation and hypoxia. ${ }^{23-27}$ Therefore, abnormalities in the regulation of RNA pol I and II transcription might provide plausible explanations for many of the somatic features, including aspects of neurological symptoms associated with CS. Observation of neurological symptoms detected either at birth or during early childhood raises the possibility that CSB may have a crucial role in the transcriptional programs that govern the plasticity and the maintenance of the central nervous system during (perinatal and postnatal) pediatric life. The neurogenesis process, initiated by neural stem cells (NSC), continues during adult life involving the generation of new neurons and other cell types thereby maintaining the turnover of neural cells and cognitive plasticity. ${ }^{28,29}$ Further, it is well established that generation and migration of neurons is crucial not only for postnatal brain enlargement but also for establishing normal synaptic connection and functionality in the brain. ${ }^{30}$

\footnotetext{
${ }^{1}$ Unit of Molecular Genetics of Aging, Department of Ecology and Biology_University of Tuscia, 01100 Viterbo, Italy; ${ }^{2}$ Department of Haematology, University of Cambridge, Cambridge CB2 OPT, UK and ${ }^{3}$ Department of Radiation Oncology, Center for Radiological Research, Columbia University Medical Center, New York, NY 10032, USA

*Corresponding author: L Proietti-De-Santis, Scienze Ecologiche e Biologiche, Università degli Studi della Tuscia, Largo dell'Università snc, 01100 Viterbo, Italy. Tel: +39 0761 357211; Fax: +39 0761 357249; E-mail: proietti@unitus.it

or AS Balajee, Department of Radiation Oncology, Center for Radiological Research, Columbia University Medical Center, New York, NY 10032, USA; Tel: +1 212 342 6838; Fax: +1 212305 3229; E-mail: ab836@columbia.edu

Keywords: Cockayne syndrome; neurodegeneration; neurogenesis; neuritogenesis; chromatin remodeling complexes; transcription complex assembly and progeroid syndromes

Abbreviations: DAPI, 4,6-Diamidino-2-phenylindole nuclear staining; UV, ultraviolet; EGF, Epidermal growth factor; FGF, Fibroblast growth factor; HRP, horseradish peroxidase

Received 24.2.14; revised 28.3.14; accepted 14.4.14; Edited by A Verkhratsky
} 
A recent article has described that an early and limited window of postnatal neurogenesis that occurs in the subventricolar zone (SVZ) is associated with a major migratory pathway that targets these new neurons not only to the olfactory bulb but also to the human prefrontal cortex. ${ }^{31}$ In support, postnatal neurogenesis was reported during the functional development of cerebellum until 18 months. ${ }^{32,33}$ Our principal hypothesis is that CS patients are not able to support brain plasticity and repair events occurring at perinatal and postnatal stages resulting in severe neurodegeneration. Therefore, a systematic evaluation of the role of CSB in neurogenesis is mandatory for exploring the molecular cause for neurodegeneration in CS patients. In this study, we used human immortalized (ReNcell VM) neural progenitor cells with efficient self-renewal and multilineage differentiation capabilities to gain insights into the role of CSB in neurogenesis. Our study provides evidence that CSB deficiency affects neuronal differentiation capabilities of human neural progenitor cells suggestive of a crucial role for CSB in adult neurogenesis.

\section{Results}

CSB suppression dramatically affects neuronal differentiation. To induce neuronal differentiation, cells were seeded on poly-L-Ornithine and Laminin-coated slides/dishes and cultured without epidermal growth factor (EGF) for an additional 3 days. Growth medium without EGF and fibroblast growth factor (FGF) was then replaced every 3 days to promote the generation of neurons, oligodendrocytes and astrocytes. Differentiation of ReNcell VM cells into neurons, oligodendrocytes and astrocytes was achieved at days 10, 17 and 24, respectively. Technical procedure followed for neuronal differentiation is shown in Figure 1a and in accordance with differentiation protocol, typical neurite outgrowth and establishment of neuronal polarity were visualized by Tuj1 staining at day 10 (Figure 1b). Successful accomplishment of differentiation of the neural progenitor cells into neurons was indicated by the strong upregulation of one of the neuronal markers, microtubule-associated protein 2 (MAP2) and downregulation of the cell proliferation marker Ki67 (Figure 1c).

To evaluate the role of CSB in human neurogenesis, we employed a lentiviral-based strategy. Control (Scrambled non-specific) and CSB-specific shRNA vectors were used to create a CSB-proficient cell line (sh-K) and a CSB-suppressed cell line (sh-CSB), respectively (Figure 1d). Stably transduced cells were selected by puromycin $(2 \mu \mathrm{g} / \mathrm{ml})$ resistance. Both RT-PCR and western blot analyses of puromycin resistant ReNcell VM cells showed a good suppression of CSB expression (more than $80 \%$ ) in sh-CSB cell line relative to scrambled vector-transfected cells (Figure 1e). A hallmark feature of CSB-deficient human and hamster cells is their increased sensitivity to UV-C radiation. ${ }^{11}$ To determine whether sh-K and sh-CSB lines were sensitive to UV-C radiation, cells were exposed to $10 \mathrm{~J} / \mathrm{m}^{2}$ of UV-C radiation. As expected, sh-CSB neural progenitor cells showed increased apoptotic death relative to sh- $K$ cells (Figure 1f). This observation clearly demonstrates that the CSB knockdown neural progenitor cells exhibit a typical UV sensitive phenotype, a characteristic feature of CSB deficiency.

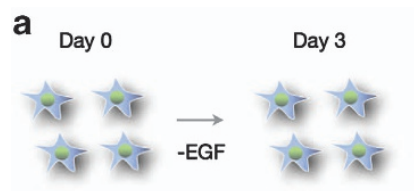

b
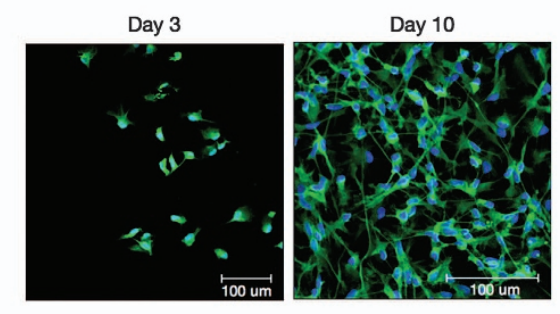

C

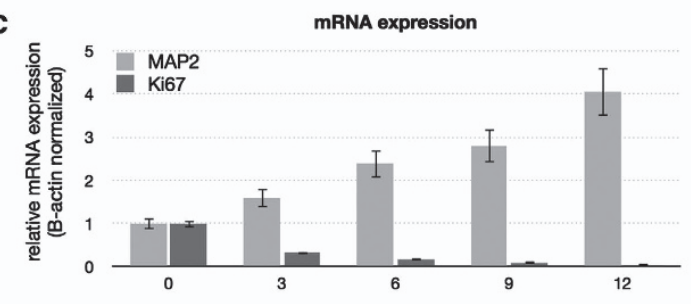

d
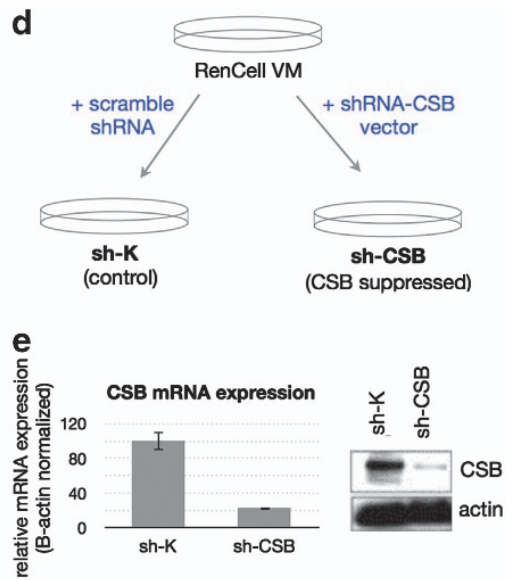

f

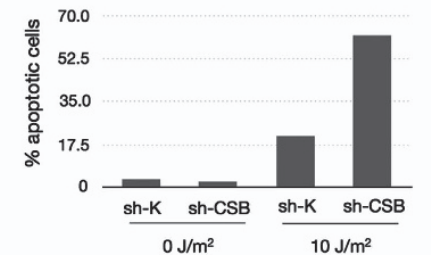

Figure 1 (a) Schematic diagram showing the procedural steps involved in the differentiation of human neural progenitor cells (RenCell VM) into neurons and glial cells. RenCell VM cell line is endowed with efficient self-renewal and multilineage differentiation capabilities. (b) Immunofluorescence staining for neuronal marker Tuj1 in sh-K cells at days 3 and 10 of differentiation. (c) Quantitative analysis of neuronal MAP2 and stem Ki67 markers expression at different times of differentiation (mean \pm S.D. of three independent experiments). (d) Schematic diagram illustrating the technical procedure followed for the generation of stably transfected cell lines with empty vector (sh-K) and CSB shRNA vector (sh-CSB) used in this study. (e) Analysis of CSB mRNA expression by RT-PCR in normal and CSB-suppressed cells (left panel) and western blotting analysis of CSB protein expression (right panel). (f) Histogram illustrates the percentage of apoptotic cells in mock and UV-treated cells (mean \pm S.D. of three independent experiments) 
Therefore, we used this cell model system to evaluate the role of CSB in neurogenesis. More specifically, we wanted to determine whether or not $c s b$ gene is crucial for viability and differentiation capabilities of NSC. Upon addition of neuronal differentiation medium, sh-K ReNcell VM cells showed prominent neuronal differentiation starting at day 9-12, with a marked neurite extension (Figures $2 \mathrm{a}-\mathrm{c}$ and $\mathrm{g}-\mathrm{i}$ ). In contrast, neuronal differentiation was greatly diminished in sh-CSB neural progenitor cells (Figures $2 d-f$ and $l-n$ ). Neurite outgrowth, a characteristic feature of differentiating neurons, was greatly abolished in CSB-suppressed cells.
Further, immunostaining intensity of fluorescein conjugated neuronal cytoplasmic marker B-tubulin III (Tuj1) was reduced in sh-CSB cells with an absolute lack of neuronal polarity.

Neuritogenesis and growth cone pathfinding are affected in CSB-suppressed cells. As shown in sh-K cells (Figures $3 a-d)$, shortly after the initiation of differentiation process (6-8 days) and preceding the initial neurite outgrowth, ruffling on the cell surface, which is primarily due to disruption of the subcortical actin network (F-actin), was observed. During neuritogenesis, the lamellipodium
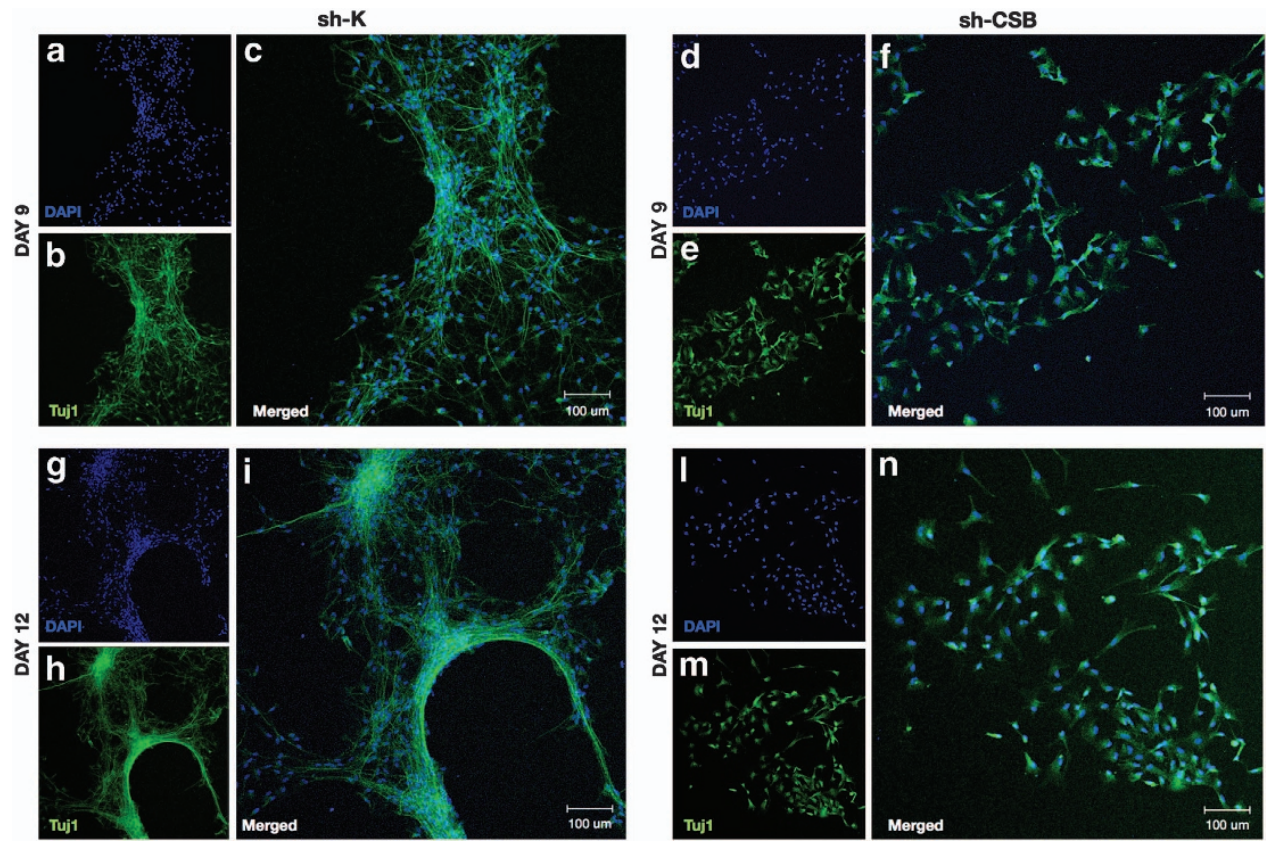

Figure 2 Immunofluorescence staining for neuronal marker Tuj1 in sh-K (a-c and $\mathbf{g - i})$ and sh-CSB (d-f and I-n) cells after differentiation at days 9 and 12 . Cells were counterstained for DNA using 4',6-diamidino-2-phenylindole
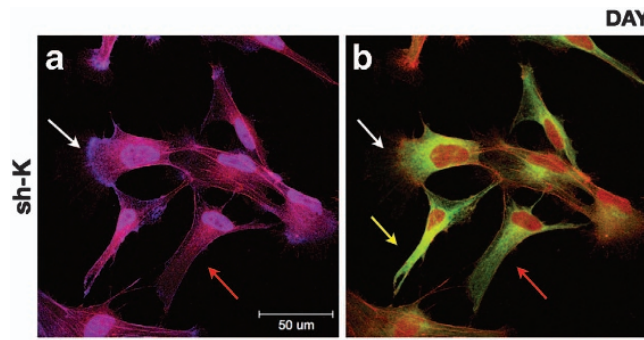

DAY 6-8
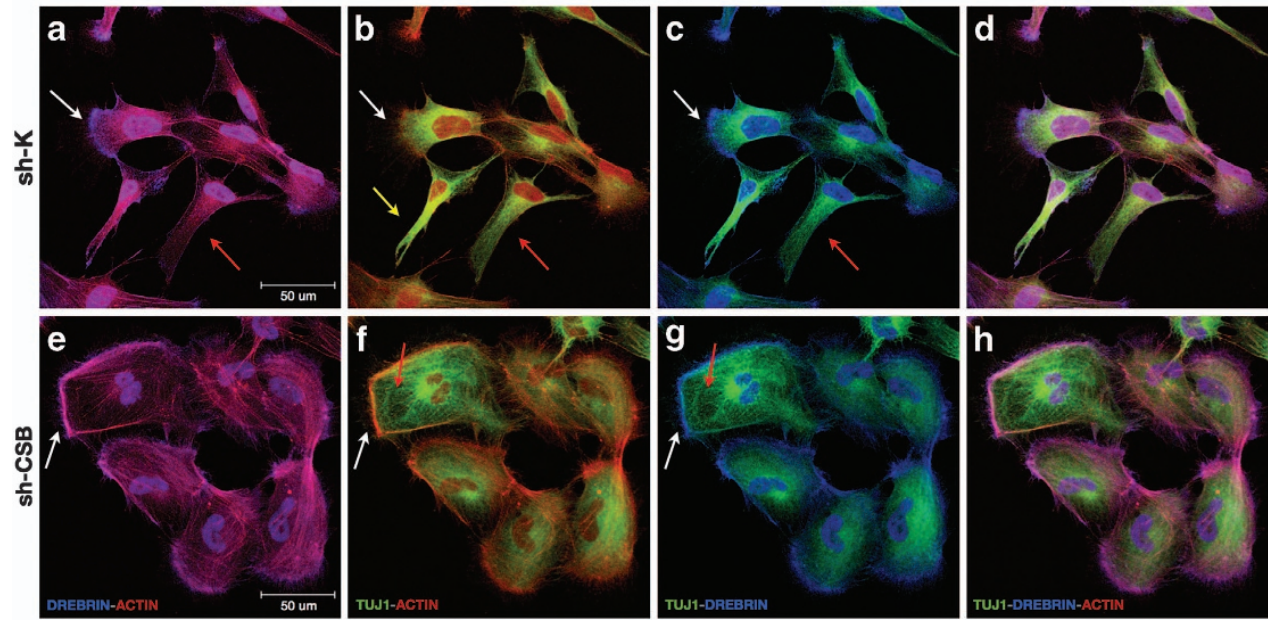

Figure 3 Immunofluorescence staining for Tuj1, Drebrin and actin in sh-K (a-d) and sh-CSB (e-h) cells after differentiation at days 6-8. In a-d, arrow indicates three different stages of neuritic outgrowth: growth cone formation (white arrow), elongation of the new formed growth cone (red arrow) and microtubules packaging inside the nascent neurite (yellow arrow). In $\mathbf{e}-\mathbf{h}$, white arrow indicates no destabilization of subcortical actin network and red arrow indicates absent advancement of microtubules within the lamollipodium, both as occuring in sh-CSB cells 
becomes segmented at one or more sites followed by extension from the soma leading to the formation of growth cone (visualized by combined staining of actin and drebrin) concurrent with advancement of microtubules (MT) into the initiation site and formation of an ordered microtubule array (white arrow). The newly formed protrusion then elongates (red arrow) and MT become tightly packed into parallel arrays inside the nascent neurite shaft (yellow arrow). Actinmicrotubule interactions were observed in lamellipodia at all stages of neurite outgrowth. All of these processes of neuritogenesis were detected in CSB-proficient cells (Figures 3a-d).

In contrast, upon CSB suppression, the subcortical actin network was not destabilized and a fairly uniform lamellipodium (F-actin) surrounding cell soma was observed with drebrin extensions (Figures $3 \mathrm{e}-\mathrm{h}$, white arrow). Further, MT were not found to interact with either actin or drebrin and the cells showed an increased cytoplasmic volume. These morphological features seemed to suggest the lack of cell polarity and motility in CSB-suppressed neural cells (Figures 3e-h, red arrow).

Although no quantitative analysis was done, it was observed that the nuclei of CSB-suppressed cells appeared to have kidney-shaped morphology and were slightly bigger than the nuclei of CSB-proficient (sh-K) cells. It is not entirely clear whether CSB suppression alters the morphology of nuclei through modulation of DNA metabolic activities. Interestingly, morphology of the two cell lines differed noticeably when sh-K and sh-CSB cells were grown for longer times in neuronal differentiation medium (Figure 4). In sh- $K$ cells $(a-d)$, the neuronal differentiation appeared to be completed after 15-18 days after the addition of differentiation medium. A complex network of neurites, visualized by Tuj1 immunostaining, showed the connective network between adjacent neurons; actin staining was found confined to the soma as well as the drebrin indicating the completeness of neuritogenesis process. In contrast, neuritogenesis was greatly reduced in sh-CSB cells $(e-h)$ as judged by the lack of connecting network of neuritic growth between adjacent cells. Strikingly, CSB-suppressed cells displayed lack of polarization and abortive growth cone-like structures visualized by actin and drebrin staining. Further, tubulin, which is not part of this external structure, appeared to be dispersed in the cytoplasm.

MAP2 expression is reduced in CSB-suppressed cells. Studies on the dynamics of cytoskeletal components during neuritogenesis have implicated actin, tubulin and MAPs in sprouting. Actin, in association with surface adhesion molecules, has an important role in the pathfinding of the processes. MT enter the growth cone to initiate neurite extension and this process appears to be facilitated by MAPs, in particular MAP2. Cunningham et al. ${ }^{34}$ demonstrated that MAP2c initiates neurite outgrowth through its interaction with the subcortical actin network. It has been suggested that the interaction of MAP2c with the actin-rich subcortical network might be responsible for the switch from an actin-based lamellar structure to a microtubule-based neuritic structure during neuritogenesis. Observation of highly reduced neuritogenesis in sh-CSB cells led us to hypothesize that MAP2c expression may be deregulated by lack or reduced CSB expression.

A time course analysis of MAP2c protein accumulation during differentiation revealed a clear difference between CSB-proficient (sh-K) and CSB-suppressed (sh-CSB) cells. Western blotting performed at different times during differentiation (Figures $5 a$ and b) showed upregulation of MAP2c protein in normal cells with a peak of activation at day 12 . In contrast, MAP2 induction was respectively five and ninefold less in sh-CSB cells, at days 12 and 15. Immunofluorescence studies were also performed at days 12 and 24 to analyze the expression of MAP2 in parallel with GFAP (Glial Fibrillary Acidic Protein) a glial marker expressed in neural progenitor cells. Representative pictures shown in Figure $5 c$ showed that expression of MAP2 peaked at day 12 in the majority of cells and then declined at day 24 with a gradual increase in GFAP-positive cells, reflecting the gradual time-dependent progression from neurons to glial cell populations. In contrast
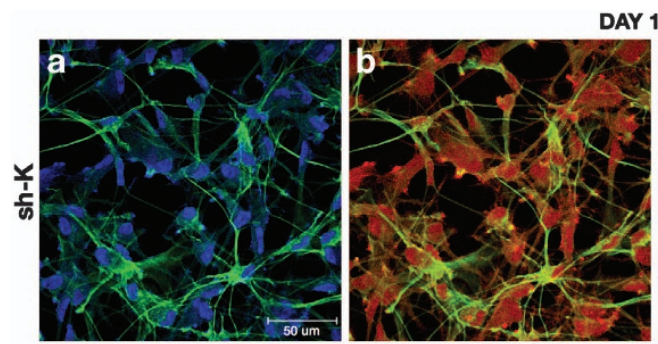

DAY 15-18
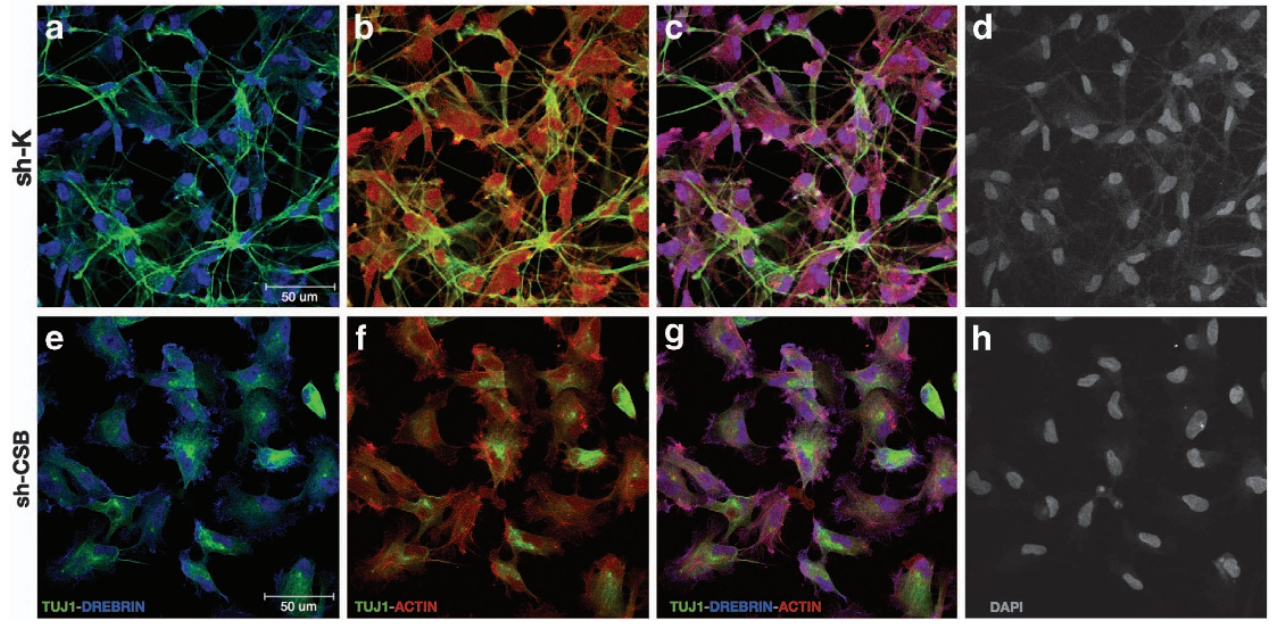

Figure 4 Immunofluorescence staining for Tuj1, Drebrin (an F-actin associated protein) and actin in sh-K (a-d) and sh-CSB (e-h) cells after growth in differentiation medium at 15-18 days. Cells were counterstained for DNA using 4',6-diamidino-2-phenylindole nuclear staining 

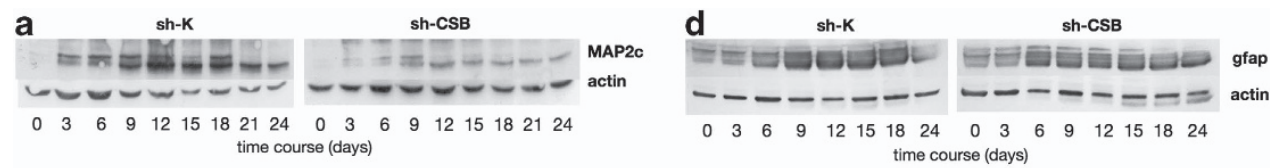

b

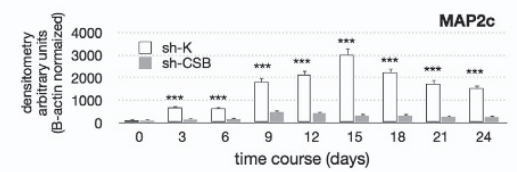

e

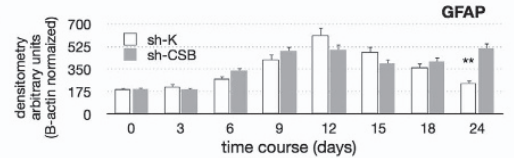

C

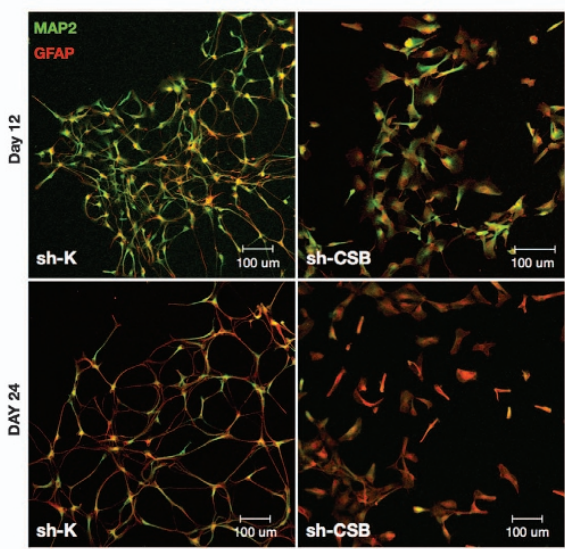

f

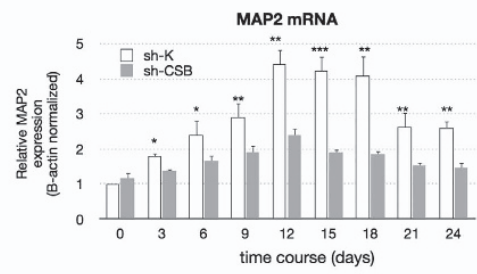

g

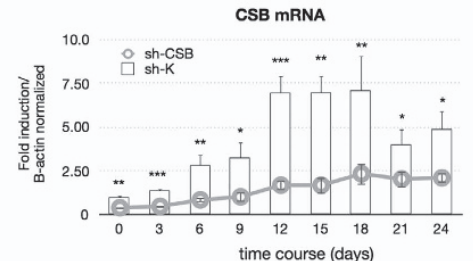

Figure 5 (a) Western blot analysis of MAP2 and $\beta$-actin expression detected in the whole cell extracts (WCE) of sh-K and sh-CSB cells during the entire time course of neural differentiation. WCE were collected at the indicated times. (b) Histogram showing quantification of MAP2 protein expression (mean \pm S.D. of three independent experiments) during neural differentiation using Image J software (NIH). Data have been normalized by $\beta$-actin. (c) Immunofluorescence staining for MAP2 and GFAP in sh-K and sh-CSB cells at days 12 and 24 of differentiation. (d) Western blot analysis of GFAP and $\beta$-actin proteins detected in the WCE of sh-K and sh-CSB cells during the entire time course of neural differentiation. Protein extracts were collected at the indicated times. (e) Histogram shows the quantification of GFAP (mean \pm S.D. of three independent experiments) during neural differentiation using Image $\mathrm{J}$ software $(\mathrm{NIH})$. Data have been normalized by $\beta$-actin. MAP2 (f) and CSB (g) mRNA expression analysis in sh-K and sh-CSB cells during the entire time course of neural differentiation (mean \pm S.D. of three independent experiments). ${ }^{* \star} P<0.001,{ }^{\star \star} P<0.01,{ }^{*} P<0.05$, (unpaired two-tailed Student's $t$-test)

to CSB-proficient cells, sh-CSB cells displayed a much lower content of MAP2, defects in neuritic outgrowth and neuronal polarity were also apparent (Figures $5 d$ and e). Furthermore, expression of both neuronal and glial markers (MAP2 and GFAP) were simultaneously detected in sh-CSB cells indicating that the differentiation programs are somewhat distorted and the transition stage between neurons and glial cells less defined or the cells were not entirely committed to differentiate. However, GFAP expression (assayed by both western blot and immunofluorescence techniques) was found to be grossly similar between sh-K and sh-CSB cells at the earlier step of the differentiation, while significantly higher in sh-CSB at the later times of the differentiation (Figures 5d and e), demonstrating that the GFAP expression was not drastically altered by CSB deficiency during the early phase of differentiation.

To determine whether the reduced expression of MAP2 observed in CSB-suppressed cells was a consequence of a reduction of its transcriptional level, MAP2 mRNA expression was monitored by quantitative RT-PCR (Figure 5f). MAP2 mRNA level increased in CSB-proficient cells during differentiation and MAP2 induction began at day 3 (1.6-fold induction) and reached its maximum at day 12 (4.5-fold induction). In contrast, MAP2 expression was consistently reduced by $\sim 50 \%$ in CSB-suppressed cells (2.3-fold induction, at day 12). CSB-dependent induction of MAP2 during the differentiation process led us to investigate whether or not CSB expression is also changing during the differentiation process (Figure $5 \mathrm{~g}$ ). Intriguingly, CSB mRNA was also induced during differentiation in normal cells starting to be noticeable at day 6 and reaching its peak at day 12, exhibiting kinetics of induction similar to MAP2. A similar trend for CSB was also observed in CSB-suppressed cells albeit much reduced due to suppression of CSB by shRNA. These findings clearly indicate that optimal csb gene dosage is required for efficient neurogenesis.

CSB interacts with nBAF complex. Although CSB has been shown to interact with some of the functional units of basal transcription factor TFIIH and RNA polymerase elongation complexes, ${ }^{35}$ identification of additional proteins and protein complexes interacting with CSB would help to unravel some of the yet unidentified functions of CSB. With this objective, tandem affinity purification (TAP) tag technology coupled with mass spectrometry was employed to identify the proteins associated to CSB. TAP technique is often used to isolate proteins, which can be identified by subsequent mass spectrometry analysis. ${ }^{36-38}$ In our approach, a TAP tag was cloned in frame with CSB cDNA (Figure 6a) and the construct was subsequently transfected into suitable host cells (CSIAN cell line, derived from CS patient without a functional CSB protein). CSIAN cells were 

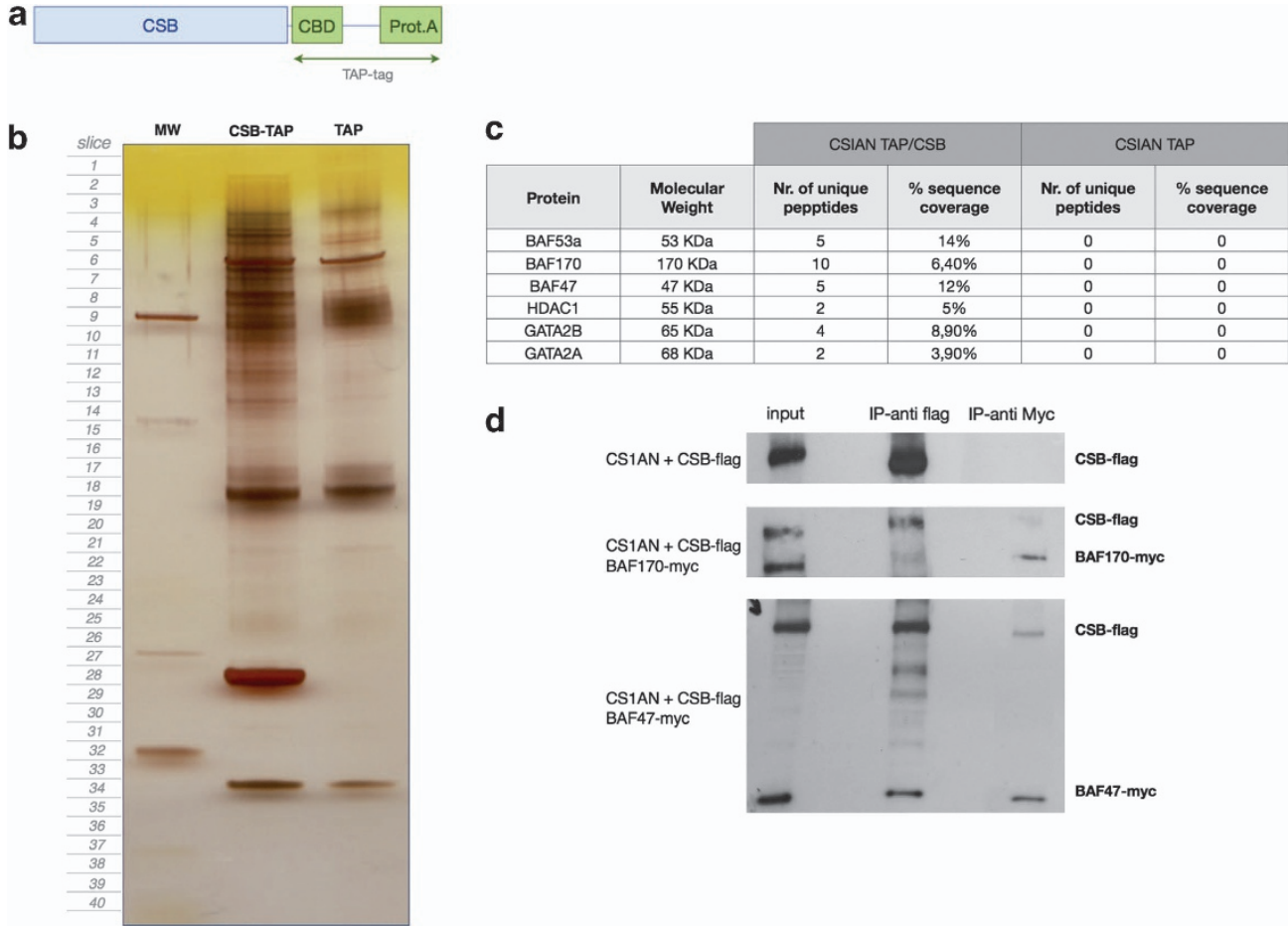

d

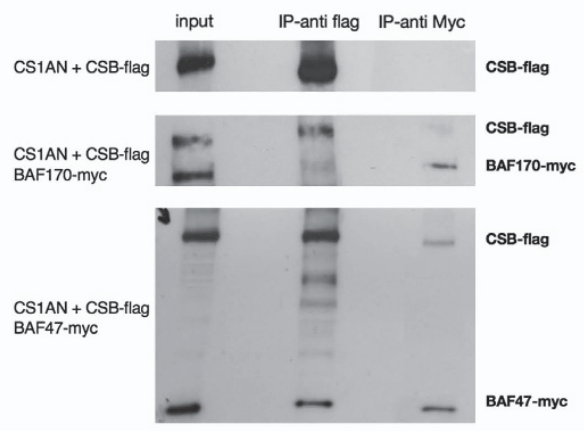

Figure 6 CSB co-precipitates with BAF complex. (a) TAP tag is fused with CSB CDNA and then cloned into a mammalian expression vector to express CSB-TAP-tagged protein. (b) Proteins associated either with CSB-TAP and or TAP alone were isolated by tandem affinity purification, separated on a 4-12\% Bis-Tris gel and visualized by silver staining. (c) Table summarizes the names and the biological processes of selected proteins co-purifying with CSB-TAP fusion protein, but were absent in the purification from control cells expressing TAP tag alone. (d) WCE prepared from CSIAN cells with stable expression of CSB-flag and transient expression of BAF170-Myc or BAF47-Myc were immunoprecipitated (IP) using either flag or Myc specific antibodies. The input, the flow through (Ft) and the IP fractions were analyzed by western blotting using antibodies indicated on the right

transfected with either pZome-1-N (mock), or pZome-1-NTAP-CSB for stable expression of CSB-TAP-tagged protein. For stable transfection, CSB-deficient cells were chosen because this allows testing the functionality of the CSB-TAP protein. CSIAN cells stably expressing TAP-CSB or TAP alone were selected with puromycin $(2 \mu \mathrm{g} / \mathrm{ml})$ for 3 weeks. The selected clones were amplified and screened for the expression of TAP-tagged CSB protein. To avoid possible artifacts due to CSB-TAP overexpression, we chose a stably transfected clonal cell line, whose CSB expression level was grossly similar to the endogenous CSB level observed in CSB-proficient MRC5 cells (data not shown). Cell survival after UV exposure showed that the CSB-TAP fusion protein was indeed functional and it protected CSIAN cells from UV induced cell death relative to vector alone-transfected cells. Further, cellular resistance to UV in CSB-TAP fusion protein expressing CSIAN cells was almost identical to CSBproficient wild-type MRC5 cells (data not shown). Proteins associated with CSB-TAP were isolated through two sequential affinity purification steps, as described in Materials and Methods. Finally, the isolated proteins were size fractionated on SDS polyacrylamide gels (Figure 6b) and analyzed by mass spectrometry essentially as described before. ${ }^{39,40}$ Using this approach, we found that CSB co-purified with components of a chromatin remodeling complex (npBAF complex), which is specific for neuronal progenitor cells (Figure $6 \mathrm{c}$ ). The BAF complex consists of different subunits (BAF170, BAF53A and BAF47) all of which are known to participate in transcriptional activation through an ATP-dependent chromatin remodeling process. ${ }^{41}$ Additional proteins that act as transcriptional repressors such as HDAC1 (histone deacetylase 1), and GATA2A and GATA2B (GATA zinc finger domain containing 2A or 2B) were also found to co-purify with CSB. Some of these interactions were confirmed by protein-protein interaction studies using recombinant tagged-proteins (Figure 6d).

CSB coordinates transcription and chromatin remodeling activities on gene promoters including MAP2. Impaired neuritogenesis coupled with the reduced expression of MAP2 at mRNA and protein levels observed in CSBsuppressed cells prompted us to investigate the possibility that CSB had a role in the transcriptional regulation of MAP2 either alone or in combination with other transcription and chromatin remodeling proteins. Regulation of chromatin structure is emerging as an important level of transcriptional control during neural development. ${ }^{42-44}$

$\mathrm{SWI} / \mathrm{SNF}$ complex is a well-studied chromatin remodeler that uses the energy derived from ATP hydrolysis to regulate nucleosome mobility and chromatin accessibility. ${ }^{45}$ One such SWI/SNF-like chromatin-remodeling enzymatic complex is $\mathrm{Brg} / \mathrm{Brm}$-associated factor (nBAF) that specifically regulates dendrite growth and axon myelination. ${ }^{46}$ The fact that CSB belongs to the SWI/SNF family makes it imperative to determine the interaction of CSB with other chromatin remodeling factors that are specifically involved in neurogenesis. 
Co-purification of CSB-TAP with components of npBAF and $\mathrm{nBAF}$ complexes observed in vitro indicates the possibility that CSB may protect the functional integrity of different brain cell types (neural stem/progenitor cells, neurons and glial cells) in vivo through successful coordination of transcription and chromatin remodeling activities during neurogenesis and neuritogenesis. To further explore this exciting possibility, chromatin immunoprecipitation (ChIP) assays were performed to study the assembly of the transcriptional machinery and the chromatin remodeling factors during neuronal differentiation. We initially focused on MAP2 because of CSB suppression reduced its expression both at mRNA and protein levels. To investigate whether reduced MAP2 expression was due to defect(s) in the assembly of transcriptional apparatus, kinetics of the occupancy of RNA polymerase II and its associated factors to map2 promoter were examined by ChIP assay at different days after the initiation of differentiation process. Antibodies directed against various components of the transcription machinery were used to precipitate the genomic DNA fragments that were further analyzed by quantitative PCR (qPCR). ChIP experiments showed a significant increase in both RNA pol II and TFIIB occupancy on the map2 promoter in sh-K cells, most likely due to transcriptional activation triggered by neuronal differentiation process
(Figures $7 b$ and c). Conversely, we found that both RNA pol II and TFIIB were not recruited to the same extent on the map2 promoter in sh-CSB cells.

To gain further insights into the chromatin modifications imposed by gene activation, extent of nucleosome histone acetylation around the map2 promoter region was investigated. In particular, we focused on H3K9 acetylation, an epigenetic marker specific for transcriptionally active chromatin (Figure 7d). Strikingly, H3K9 acetylation was highly reduced at the map2 promoter in sh-CSB cells. The reduced level of H3K9 acetylation observed in sh-CSB cells seems to correlate with the impaired recruitment of the p300 histone acetyltrasferase at the map2 promoter (Figure 7e). p300 functions as an essential cofactor for adult neurogenesis. ${ }^{47}$ Further, ChIP assay revealed the presence of CSB at the map2 promoter site and the recruitment of CSB was further enriched at the promoter site during/after differentiation (Figure 7f). As expected, recruitment and retention of CSB was reduced in sh-CSB cells. It should be noticed that in sh-K cells, during differentiation, BAF complex was detected at the map2 promoter with progressive enrichments of its Brg1 and BAF170 subunits (Figures $7 g$ and $h$ ). This indicates that the positioning of BAF chromatin remodeling complex at the map2 promoter is required for its activation. Collectively, these results suggest that the reduced MAP2 expression a
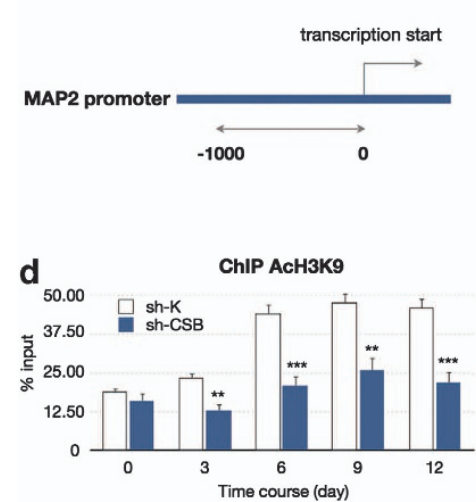

g
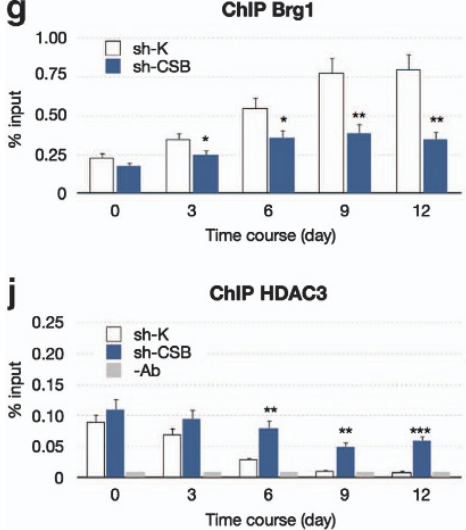

b
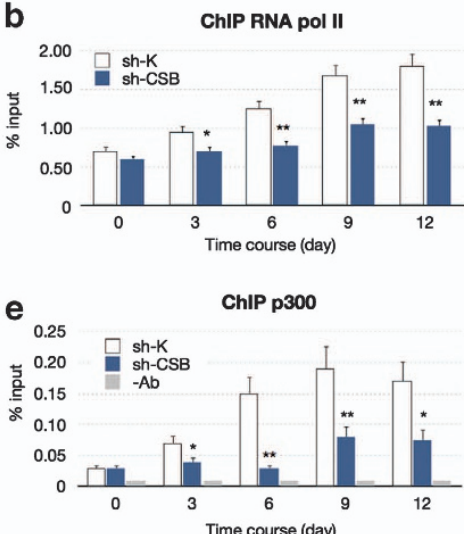

h

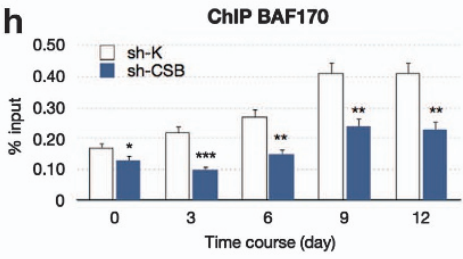

k

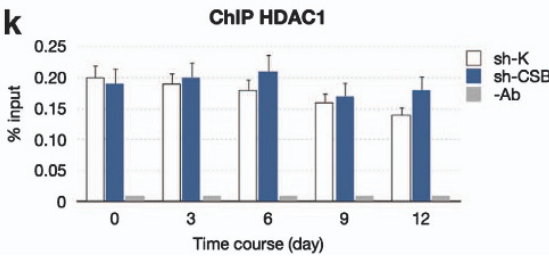

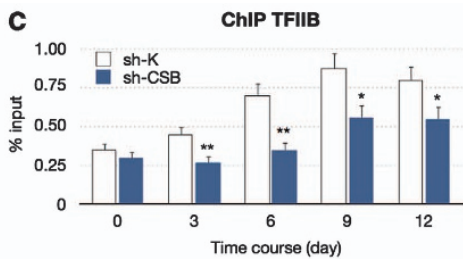
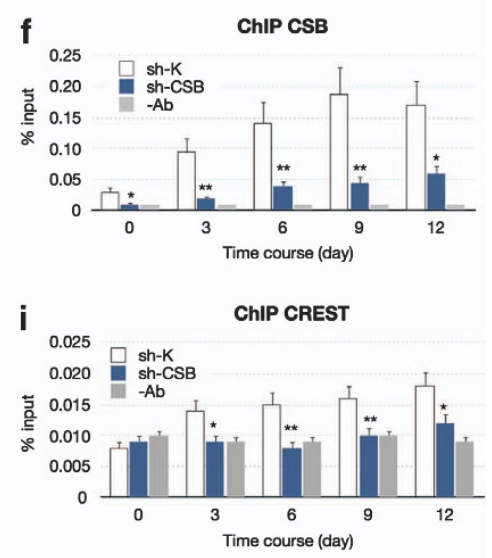

sh-K
sh-CSB
$-A b$

Figure 7 Interaction of CSB protein with transcription and chromatin remodeling factors detected by ChIP. (a) Real-time PCR was performed using gene promoter-specific primers to examine the relative enrichment for the promoter region of map2 sites immediately upstream of the transcription initiation site. Soluble chromatin was prepared from sh-K and sh-CSB cells and subjected to ChIP assay using antibodies against RNA pol II (b), TFIIB (c), K9-Acetylated histone H3 (d), p300 (e), CSB (f), Brg1 (g), BAF170 (h), CREST (i), HDAC3 (j) and HDAC1 (k). ${ }^{* *} P<0.001,{ }^{* *} P<0.01,{ }^{*} P<0.05$, (unpaired two-tailed Student's $t$-test) 
observed in CSB knockdown cells is most probably due to impaired recruitment of BAF complex on map2 promoter and that CSB is necessary for efficient assembly of transcriptional complex on this promoter. In addition, we found that the activation of map2 promoter that occurred during neural differentiation correlated well with the loss of HDAC3 in sh-K cells but not in sh-CSB cells (Figure 7j). However, there was no change in the retention of HDAC1 at the map2 promoter during neural differentiation either in sh-K or sh-CSB cells (Figure 7k). Thus, it appears that the increased binding of CSB to map2 promoter paralleled the recruitment of BAF, thereby implying a role for CSB in BAF recruitment. This is partly supported by the observation of CSB interacting to some of the subunits of the BAF complex. BAF53b, that seems essential for the recruitment of BAF complex at the gene promoter sites, does not have a DNA binding domain. Therefore, a likely possibility is that CSB can mediate the binding of BAF53b to the promoter sites. In support, interaction of CSB not only with Brg1 and BAf170 but also with Baf53 ( $a$ and $b$ ) was demonstrated. Alternatively, histone acetylation changes imposed by CSB via its interaction with HAT p300 would also facilitate the recruitment of essential factors to BAF. Both hypotheses, although not mutually exclusive, confer an important role to CSB in MAP2 gene activation during neuronal differentiation. Along this line of evidence, it has been shown that nBAF complex together with CREST has a role in regulating the activity of genes essential for dendrite growth. ${ }^{46}$

Our finding of reduced expression of MAP2 in CSBsuppressed cells prompted us to investigate the expression of yet another neuronal marker NEUROD1 in sh-K and sh-CSB cell lines. NEUROD1 mRNA expression was monitored by quantitative RT-PCR (Figure 8a). NEUROD1 mRNA level increased in CSB-proficient cells during differentiation and reached its maximum at day 15 (6.2-fold induction). In contrast, NEUROD1 expression was consistently reduced by $\sim 50 \%$ in CSB-suppressed cells (2.9-fold induction, at day 15). As observed for MAP2 promoter, also NEUROD1 promoter exhibited impaired recruitment of RNA polymerase II in CSB-suppressed cells (Figure 8c). ChIP assay also revealed the presence of CSB at the neurod1 promoter site in CSB-proficient cells and the recruitment of CSB was further enriched at the promoter site during/after differentiation (Figure 8d). As expected, recruitment and retention of CSB was reduced in sh-CSB cells due to overall reduced CSB expression in these cells.

\section{Discussion}

In this report, we demonstrate that CSB suppression affects the neuronal differentiation capability of human neural progenitor cells. Most strikingly, CSB suppression led to a highly reduced expression of MAP2 accompanied by impaired cell polarization and neuritogenesis. Collectively, these findings appear to be relevant to explain the molecular basis of at least some of the neurological symptoms reported in CS patients. Although earlier studies have addressed this aspect in double XP/CS knockout mouse model system, ${ }^{48-50}$ our study is the first to our knowledge to explore the role of CSB in neurogenesis using a human model system.

Brain has long been considered to have ceased the development beyond fetal and early postnatal stages but recent studies have demonstrated that neurons are continually generated from adult neural stem/progenitor cells in two well-defined neurogenic regions: SVZ of the lateral ventricles and subgranular zone of the dentate gyrus and for a limited period, within the white matter tracts. Moreover, NSC have been isolated in the external granular layer of the cerebellum in rodents and hence their presence in cerebellum cannot be completely excluded in human brain. ${ }^{51}$ Development of the brain structure and complexity occurring during early infancy is critical for the postnatal neurogenic activity. ${ }^{52,53}$

Homeostasis of the brain tissue requires the replenishment of neurons as well as protection of brain cell types, including neural stem/progenitor cells, against endogenous and exogenous DNA damage. Therefore, impairment of either of these processes, neurogenesis and DNA repair, is likely to result in neurodegeneration. In this study, we demonstrate

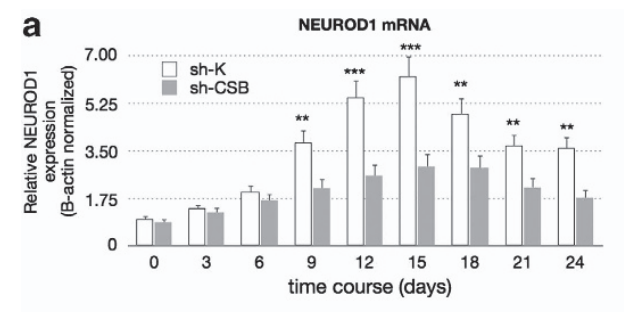

b
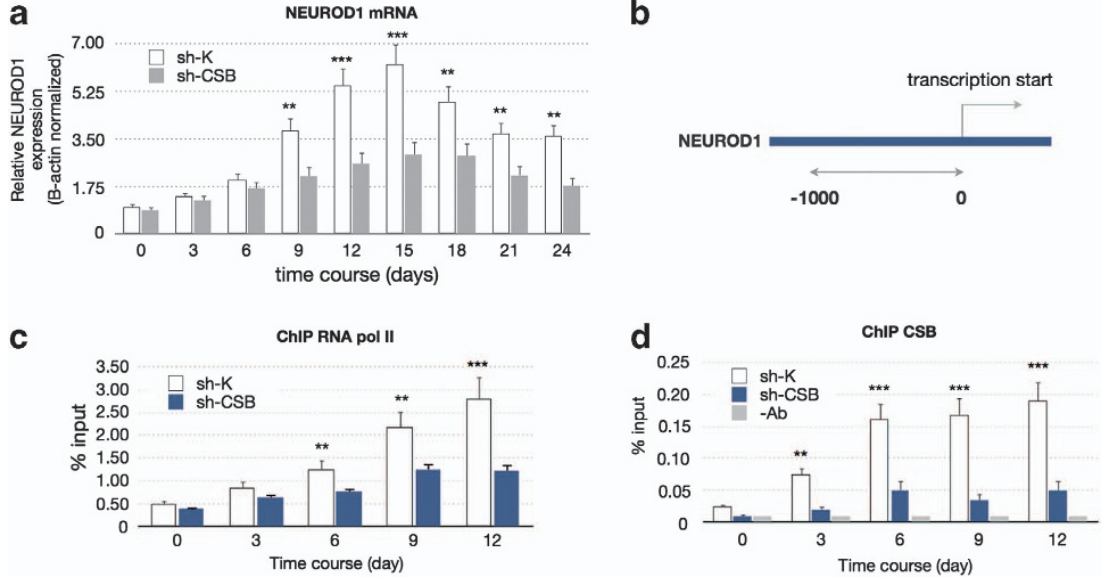

Figure 8 NEUROD1 (a) mRNA expression analysis in sh-K and sh-CSB cells during the entire time course of neural differentiation (mean \pm S.D. of three independent experiments). (b-d) ChIP analysis of RNA polymerase II and CSB recruitment on NEUROD1 promoter region. Real-time PCR was performed using gene promoter-specific primers to examine the relative enrichment of RNA polymerase II and CSB protein at the promoter region of NEUROD1 gene (b). Soluble chromatin was prepared from sh-K and sh-CSB cells and subjected to ChIP assay using antibodies against RNA pol II (c) and CSB (d) 
that the efficient differentiation of neural progenitor cells into neurons requires a functional csb gene product. Impaired neuronal differentiation coupled with reduced expression of neuronal-specific marker MAP2 in CSB-suppressed cells strongly indicate that $c s b$ gene is pivotal for the neuronal differentiation process. Thus, the positive correlation observed between CSB deficiency and defective neurogenesis in the present study suggests that the neurological symptoms observed in CS patients are indeed primarily due to CSB deficiency but not to secondary effects. It is reasonable to assume that a defect in the postnatal development of prefrontal cortex due to lack of postnatal neurogenesis may result in features such as microcephaly that characterize CS. Likewise, a deficiency in neurogenesis in the subcortical white matter could also account for the dysmyelination/demyelination features displayed by CS. Along these lines, defective neurogenesis particularly in the cerebellum could account for the cerebellar degenerative features displayed by CS patients. Alternately, an additive effect of defective neurogenesis superimposed by TCR defect can also contribute to other neurological aspects including cataract and cerebellar atrophy in CS patients.

In contrast to our findings, a recently published article reported that the neural precursor functions are not affected in CSB-deficient mice. ${ }^{50}$ It was previously established that the neurological symptoms in CSB-deficient mice are not as severe as in humans and that CSB mouse model system does not recapitulate the human CSB phenotype. Severe neurological symptoms in human CSB patients can only be induced in mice after functional inactivation of $c s b$ in combination with $x p c$ (xeroderma pigmentosum complementation group $\mathrm{C}$ ) gene. ${ }^{48}$ In this context, it is known that XP mutations in human confer neurologic defects per se, which however differ from that associated with $\mathrm{CS}$. Although $\mathrm{XP}$ is a primarily neurodegenerative disease ${ }^{54,55}$ owing to the degeneration of neurons, CS appears to be more of a neurodevelopmental disease because of the neurologic features such as early microcephaly, cerebellar hypoplasia and hypomyelination.

The onset of neurological defects observed after birth in CS patients raises an intriguing question: why is the CSB protein essential for adult neurogenesis but not during embryonic brain development? Strikingly, patients either with the classical form (CS type 1) or congenital form (CS type II) display normal intrauterine somatic and brain growth with developmental crisis after birth: immediately after birth in type II, in the first or second year of life in type I. This led us to hypothesize that the $c s b$ gene is dispensable during the fetal stage but not during postnatal development. Manifestation of developmental defects especially of neurological symptoms after birth of CS patients led us to postulate that $c s b$ gene may perform essential functions during the extrauterine life when the child is no longer protected by the controlled environment in mother's womb in terms of angiogenic factors and gaseous oxygen. Oxygen homeostasis could very well represent one of the Achilles' heel of CS patients during extrauterine life, which is amply supported by an abnormal transcriptional response of CSB-deficient cells to hypoxia involving HIF-1 (hypoxia inducible factor-1)-mediated signaling pathway. ${ }^{24}$ HIF-1 is implicated in the regulation of a vast array of genes that control multiple cellular functions such as angiogenesis, glucose metabolism and cell survival. This finding might have great implications for neurodegeneration in CS because the oxygen tension in brain is lower than in other organs/tissues and therefore optimal activation of HIF-1 pathway is crucial for the functional integrity of brain cell types including neural stem/ progenitor cells. Another likely possibility is that hypoxia in certain metabolically active regions of brain may stimulate ROS production in a mitochondrial dependent fashion ${ }^{56}$ and increased ROS production in turn can lead to DNA damage accumulation resulting either in senescence or cell death. In corroboration, we observed an increased fraction of senescent cells with exacerbation of defects in neurogenesis when CSB-suppressed neural progenitor cells are grown under hypoxic conditions (Supplementary data 1).

Observations of localization of CSB protein in mitochondria and its role in the repair of mitochondrial oxidative DNA damage further add a new dimension to the multitude of complex cellular functions of CSB in maintaining the functional integrity of mitochondria. ${ }^{57} \mathrm{~A}$ recent paper has demonstrated that CSB prevents the accumulation of damaged mitochondria by promoting mitochondrial autophagy. ${ }^{58}$ CSB also promotes the transcriptional elongation in mitochondria through communications with mitochondrial proteins. ${ }^{59}$ As brain cells are metabolically highly active, protection of mitochondrial DNA from excessive generation of ROS and RNS is crucial for the integrity of brain cells. Therefore, loss of CSB is expected to lead to deleterious effects in terms of neuronal loss owing to enhanced DNA damage accumulation in addition to the impact on neurogenesis. Collectively, our findings suggest a multifaceted role for CSB not only in neurogenesis but also in protecting the functional integrity of neural progenitor cells under low oxygen tension through transcriptional activation of factors involved in hypoxia signaling pathway.

Given that MAP2 is a neuronal marker, reduced amount of MAP2 observed in CSB-suppressed neural progenitor cells may be viewed per se as a simple consequence of a reduced number of neurons. Interestingly, demonstration of transcriptional regulation of MAP2 by CSB indicates that the reduced MAP2 expression is primarily due to CSB deficiency and not due to reduced neuronal differentiation. It is currently unclear whether optimal MAP2 expression is in fact the driving force for neuronal differentiation besides its role in neuritic outgrowth. Although we cannot exclude this, a likely possibility is that CSB may also participate in the transcriptional activation of other genes essential for neurogenesis. This possibility is greatly strengthened by our finding of the reduced expression of NEUROD1 in CSB knockdown cells and that neurod1 promoter is also bound by CSB. Therefore, it is highly likely that CSB upregulates those genes that are essential for neuronal differentiation through chromatin opening/remodeling activities as described in the case of map2. Although additional experiments are clearly warranted for unraveling the functional complexity of CSB in neurogenesis, this study in our opinion has paved the way for future mechanistic studies.

\section{Materials and methods}

Cell culture, silencing and differentiation. ReNCell VM cells were grown as an adherent monolayer on poly-ornithine $(0.002 \%)$ laminin $(2 \mu \mathrm{g} / \mathrm{ml})$ coated tissue culture flasks in the presence of $20 \mathrm{ng} / \mathrm{ml}$ of human recombinant 
EGF and bFGF2 in DMEM:F12 medium with nutrients optimized for neural progenitor cell growth. Cells in exponential growth phase, were transduced with lentiviral particles ( $1 \times 105$ infectious units of virus) containing either three targetspecific constructs that encode 19 nt (plus hairpin) shRNA designed to knockdown CSB gene expression (Santa Cruz Biotechnology, sc.37794-V) or shRNA nontargeting control (Santa Cruz Biotechnology, Dallas, TX, USA; sc.108080). Puromicin selection $(2 \mu \mathrm{g} / \mathrm{ml})$ is performed to achieve stable gene silencing. Withdrawal of the growth factors from the maintenance medium, as depicted in Figure 1a resulted in the spontaneous differentiation of these progenitor cells. Immunofluorescence labeling of differentiating neural progenitor cells ReNCell VM cells grown on Laminin-coated glass coverslips were induced to differentiate, fixed in paraformaldehyde and incubated with monoclonal antibodies against class III beta-tubulin (MMS-435P, Covance, Princeton, NJ, USA), polyclonal anti-MAP2 (AB15452, Millipore, Billerica, MA, USA), polyclonal anti-GFAP (AB18-0063, Invitrogen, Carlsbad, CA, USA), polyclonal anti-drebrin A/E (AB10140, Millipore), followed by incubation with fluorochrome-conjugated secondary antibodies. Actin was stained using Rhodamine-phalloidin (R415, Molecular Probes, Carlsbad, CA, USA) staining. Slides were analyzed with a confocal microscope system (Zeiss LSM 710, Oberkochen, Germany).

Construction of tagged vector, transfection and selection. The mammalian CSB expression plasmid used in the TAP technique (pZome-1-NTAP-CSB) has been generated by inserting the full-length coding region of human CSB cDNA into the BamHI site of pZome-1-N (Euroscarf, Heidelberg, Germany). In this construct, the TAP tag consists of the protein A (Prot. A) and the calmodulin-binding peptide affinity sequences that are separated by the recognition sequence for tobacco etch virus (TEV) protease, permitting proteolytic elution of the fusion protein from the IgG affinity resin. CSIAN (CSB deficient), normally grown in DMEM/F10 medium containing $10 \%$ serum and antibiotics, have been transfected with either pZome-1-N (mock), or pZome-1-N-TAP-CSB using JetPEI (Polyplus) DNA transfection reagent. CSIAN cells stably expressing TAPCSB or TAP alone were selected with puromycin $(0.3 \mu \mathrm{g} / \mathrm{ml})$ for 3 weeks.

Western blot analysis. Cells were lysed for $10 \mathrm{~min}$ on ice in RIPA buffer. The whole cell extracts were centrifuged at $13000 \times \mathrm{g}$ for $5 \mathrm{~min}$ and the supernatant was recovered. Protein concentration was determined by Bradford protein assay kit (BioRad, Hercules, CA, USA). Proteins (50 $\mu \mathrm{g})$ were separated on polyacrylamide gradient gel (4-20\%) electrophoresis and blotted onto PVDF membrane (Amersham, Pittsburgh, PA, USA) following the standard procedures. The membrane was incubated with TBST (20 mM Tris-HCl, pH 7.4, $137 \mathrm{mM} \mathrm{NaCl}$; $0.2 \%$ Tween 20) buffer containing $5 \%$ non-fat dried milk for 60 min at RT and subsequently incubated with primary and horseradish peroxidase-conjugated secondary antibodies (Vector, Burlingame, CA, USA). The signal was detected using the enhanced chemiluminescence method following the manufacturer's instructions (Amersham). Antibodies against actin (sc-47778) and CSB (sc-25370) were purchased from Santa Cruz Biotechnology. Antibodies against Flag (F3165) and Myc (C3956) were purchased from Sigma Aldrich (St. Louis, MO, USA).

Retrotranscription and real-time qPCR. RNA was isolated using the NucleoSpin RNA II kit (Macherey-Nagel, Duren, Germany). cDNA synthesis was performed using the First Strand CDNA Synthesis kit (Fermentas, Vilnius, Lithuania). Real-time qPCR was carried out with SYBR green master mixture (Promega, Fitchburg, WI, USA) using Mx3005P Real-Time PCR system (Agilent, Santa Clara, CA, USA). Results were normalized to $\beta$-actin. Primers sequences are available upon request.

TAP. The cells were scraped from plates in ice-cold PBS and pelleted by centrifugation at $2000 \times \mathrm{g}$ for $10 \mathrm{~min}$ at $4{ }^{\circ} \mathrm{C}$. After removal of excess PBS, the cell pellet $(30 \mathrm{ml})$ was resuspended in $60 \mathrm{ml}$ of ice-cold IPP150 lysis buffer ( $50 \mathrm{mM}$ Tris pH 8.0, $150 \mathrm{mM} \mathrm{NaCl}, 10 \%$ glycerol, $0.1 \%$ NP-40, complete protease inhibitors, $1 \mathrm{mM}$ PMSF). The cells were homogenized with 40 strokes in a Dounce homogenizer with a tight-fitting pestle and incubated on ice for $5 \mathrm{~min}$. Insoluble material was removed by centrifugation at $16000 \times g$ for $20 \mathrm{~min}$ at $4{ }^{\circ} \mathrm{C}$. The cell extracts were incubated with $500 \mu \mathrm{l}$ of $\lg \mathrm{G}$ sepharose beads for $2 \mathrm{~h}$ at $4{ }^{\circ} \mathrm{C}$ on a rotating wheel. The IgG beads were washed twice with $60 \mathrm{ml}$ of ice-cold IPP150 lysis buffer and $30 \mathrm{ml}$ of TEV cleavage buffer ( $10 \mathrm{mM}$ Tris $\mathrm{pH} 8.0,150 \mathrm{mM} \mathrm{NaCl}$, $10 \%$ glycerol, $0.1 \%$ NP-40, $0.5 \mathrm{mM}$ EDTA, $1 \mathrm{mM}$ DTT). The washed IgG beads were resuspended in $2 \mathrm{ml}$ of ice-cold TEV cleavage buffer supplemented with $40 \mu \mathrm{l}$ of AcTEV protease (400 U) and complete protease inhibitors and incubated at $16{ }^{\circ} \mathrm{C}$ for $2 \mathrm{~h}$ on a rotating wheel. The TEV eluate was adjusted with $\mathrm{CaCl} 2$ to $3 \mathrm{mM}$ final concentration, mixed with $6 \mathrm{ml}$ of calmodulin-binding buffer 1 (10 mM $\beta$-mercaptoethanol, $10 \mathrm{mM}$ Tris $\mathrm{pH} 8.0,150 \mathrm{mM} \mathrm{NaCl}, 10 \%$ glycerol, $0.1 \% \mathrm{NP}-40,1 \mathrm{mM}$ imidazole, $1 \mathrm{mM}$ Mg-Acetate, $2 \mathrm{mM} \mathrm{CaCl} 2$ ) and $150 \mu \mathrm{l}$ calmodulin beads and incubated for $2 \mathrm{~h}$ at $4{ }^{\circ} \mathrm{C}$ on a rotating wheel. The calmodulin beads were washed with $30 \mathrm{ml}$ of ice-cold calmodulin-binding buffer 1 and with $20 \mathrm{ml}$ of calmodulin-binding buffer $2(1 \mathrm{mM} \beta$-mercaptoethanol, $10 \mathrm{mM}$ Tris $\mathrm{pH} 8.0,150 \mathrm{mM} \mathrm{NaCl}, 1 \mathrm{mM} \mathrm{Mg}$-Acetate, $2 \mathrm{mM} \mathrm{CaCl}_{2}$ ). The bound proteins were eluted from beads by boiling in the LDS sample buffer, separated on a $4-12 \%$ Bis-Tris gel and visualized by silver staining.

ChIP. Cells were cross-linked with a $1 \%$ formaldehyde solution for $10 \mathrm{~min}$ at RT. Cross-linking was stopped by addition of glycine to $125 \mathrm{mM}$ final concentration. Samples were sonicated to generate DNA fragments below $500 \mathrm{bp}$. For immunoprecipitations, protein extract $(1 \mathrm{mg})$ was precleared for $2 \mathrm{~h}$ with $50 \mathrm{ml}$ of a $50 \%$ slurry of $50: 50$ protein A/G-Sepharose before adding the indicated antibodies. Then, $2 \mathrm{mg}$ of p53 antibody was added to the reactions and incubated over night at $4{ }^{\circ} \mathrm{C}$ in the presence of $50 \mathrm{ml}$ of protein $\mathrm{A} / \mathrm{G}$ beads. After serial washings, the immunocomplexes were eluted twice for $10 \mathrm{~min}$ at $65^{\circ} \mathrm{C}$ and crosslinking was reversed by adjusting to $200 \mathrm{mM} \mathrm{NaCl}$ and incubating $5 \mathrm{~h}$ at $65^{\circ} \mathrm{C}$. Further proteinase- $K$ digestion was performed for $2 \mathrm{~h}$ at $42^{\circ} \mathrm{C}$. DNA was purified by using Qiagen (Valencia, CA, USA) columns (QIAquick PCR purification Kit). Immunoprecipitated DNA was quantified by real-time $\mathrm{qPCR}$. Primers sequences are available upon request.

\section{Conflict of Interest}

The authors declare no conflict of interest.

Acknowledgements. This work has been supported by Telethon (GGP11176) and Italian Association for Cancer Research (AIRC-IG2012-13074).

1. Weidenheim KM, Dickson DW, Rapin I. Neuropathology of Cockayne syndrome: evidence for impaired development, premature aging, and neurodegeneration. Mech Ageing Dev 2009; 130: 619-636.

2. Laugel V, Dalloz C, Durand M, Sauvanaud F, Kristensen U, Vincent MC et al. Mutation update for the CSB/ERCC6 and CSA/ERCC8 genes involved in Cockayne syndrome. Hum Mutat 2010; 31: 113-126.

3. Natale V. A comprehensive description of the severity groups in Cockayne syndrome. Am J Med Genet 2011; 155A: 1081-1095.

4. Henning KA, Li L, lyer N, McDaniel LD, Reagan MS, Legerski R et al. The Cockayne syndrome group $A$ gene encodes a WD repeat protein that interacts with CSB protein and a subunit of RNA polymerase II TFIIH. Cell 1995; 82: 555-564.

5. Troelstra C, van Gool A, de Wit J, Vermeulen W, Bootsma D, Hoeijmakers JH. ERCC6, a member of a subfamily of putative helicases, is involved in Cockayne's syndrome and preferential repair of active genes. Cell 1992; 71: 939-953.

6. Lehmann AR. Three complementation groups in Cockayne syndrome. Mutat Res 1982; 106: 347-356.

7. Venema J, Mullenders LH, Natarajan AT, van Zeeland AA, Mayne LV. The genetic defect in Cockayne syndrome is associated with a defect in repair of UV-induced DNA damage in transcriptionally active DNA. Proc Natl Acad Sci USA 1990; 87: 4707-4711.

8. Licht $\mathrm{CL}$, Stevnsner T, Bohr VA. Cockayne syndrome group B cellular and biochemical functions. Am J Hum Genet 2003; 73: 1217-1239.

9. Laine JP, Egly JM. When transcription and repair meet: a complex system. Trends Genet 2006; 22: 430-436.

10. Sarasin A, Stary A. New insights for understanding the transcription-coupled repair pathway. DNA Repair (Amst) 2007; 6: 265-269.

11. Mayne LV, Lehmann AR. Failure of RNA synthesis to recover after UV irradiation: an early defect in cells from individuals with Cockayne's syndrome and xeroderma pigmentosum. Cancer Res 1982; 42: 1473-1478.

12. Balajee AS, Proietti-De-Santis L, Brosh RM, Selzer R, Bohr VA. Role of the ATPase domain of the Cockayne syndrome group B protein in UV induced apoptosis. Oncogene 2000; 19: 477-489.

13. Aamann MD, Muftuoglu M, Bohr VA, Stevnsner T. Multiple interaction partners for Cockayne syndrome proteins: implications for genome and transcriptome maintenance. Mech Ageing Dev 2013; 134: 212-224.

14. Caputo M, Frontini M, Velez-Cruz R, Nicolai S, Prantera G, Proietti-De-Santis L. The CSB repair factor is overexpressed in cancer cells, increased apoptosi resistence, and promotes tumor growth. DNA Repair 2013; 12: 293-299. 
15. Brooks PJ. Blinded by the UV light: how the focus on transcription-coupled NER has distracted from understanding the mechanisms of Cockayne syndrome neurologic disease. DNA Repair 2013; 12: 656-671.

16. Balajee AS, May A, Dianov GL, Friedberg EC, Bohr VA. Reduced RNA polymerase ॥ transcription in intact and permeabilized Cockayne syndrome group B cells. Proc Natl Acad Sci USA 1997; 94: 4306-4311.

17. Selby $C P$, Sancar A. Cockayne syndrome group B protein enhances elongation by RNA polymerase II. Proc Natl Acad Sci USA 1997; 94: 11205-11209.

18. Tantin D, Kansal A, Carey M. Recruitment of the putative transcription-repair coupling factor CSB/ERCC6 to RNA polymerase II elongation complexes. Mol Cell Biol 1997; 17: 6803-6814.

19. van Gool AJ, van der Horst GT, Citterio E, Hoeijmakers JH. Cockayne syndrome: defective repair of transcription? EMBO J 1997; 16: 4155-4162.

20. Bradsher J, Auriol J, Proietti de Santis L, Iben S, Vonesch JL, Grummt I et al. CSB is a component of RNA pol I transcription. Mol Cell 2002; 10: 819-829.

21. Yuan X, Feng W, Imhof A, Grummt I, Zhou Y. Activation of RNA polymerase I transcription by cockayne syndrome group B protein and histone methyltransferase G9a. Mol Cell 2007; 27: 585-595.

22. Brooks PJ, Cheng TF, Cooper L. Do all of the neurologic diseases in patients with DNA repair gene mutations result from the accumulation of DNA damage? DNA Repair 2008; 7: 834-848.

23. Proietti-De-Santis L, Drane P, Egly JM. Cockayne syndrome B protein regulates the transcriptional program after UV irradiation. EMBO J 2006; 25: 1915-1923.

24. Filippi S, Latini P, Frontini M, Palitti F, Egly JM, Proietti-De-Santis L. CSB protein is (a direct target of HIF-1 and) a critical mediator of the hypoxic response. EMBO J 2008; 27 2545-2556.

25. Frontini M, Proietti-De-Santis L. Cockayne syndrome B protein (CSB): linking p53, HIF-1 and p300 to robustness, lifespan, cancer and cell fate decisions. Cell Cycle 2009; 8: 693-696.

26. Newman JC, Bailey AD, Fan HY, Pavelitz T, Weiner AM. An abundant evolutionarily conserved CSB-PiggyBac fusion protein expressed in Cockayne syndrome. PLoS Genet 2008; 4: e1000031.

27. Velez-Cruz R, Egly JM. Cockayne syndrome group B (CSB) protein: at the crossroads of transcriptional networks. Mech Ageing Dev 2013; 134: 234-242.

28. Curtis MA, Kam M, Nannmark U, Anderson MF, Axell MZ, Wikkelso C et al. Human neuroblasts migrate to the olfactory bulb via a lateral ventricular extension. Science 2007: 315: 1243-1249.

29. Sanai N, Berger MS, Garcia-Verdugo JM, Alvarez-Buylla A. Comment on 'Human neuroblasts migrate to the olfactory bulb via a lateral ventricular extension'. Science 2007; 318: 393

30. Tau GZ, Peterson BS. Normal development of brain circuits. Neuropsychopharmacology 2010; 35: 147-168.

31. Sanai N, Nguyen T, Ihrie RA, Mirzadeh Z, Tsai HH, Wong M et al. Corridors of migrating neurons in the human brain and their decline during infancy. Nature 2011; 478: 382-386.

32. Bonfanti L, Peretto P. Adult neurogenesis in mammals-a theme with many variations. Eur J Neurosci 2011; 34: 930-950

33. Spreen O, Risser AH, Edgell D. Developmental Neuropsychology. Oxford University press: New York, 1995.

34. Cunningham CC, Leclerc N, Flanagan LA, Lu M, Janmey PA, Losik KS. Microtubuleassociated protein $2 \mathrm{c}$ reorganizes both microtubules and microfilaments into distinct cytological structures in an actin-binding protein-280-deficient melanoma cell line. J Cell Biol 1997; 136: 845-857.

35. Tantin D. RNA polymerase II elongation complexes containing the Cockayne syndrome group B protein interact with a molecular complex containing the transcription factor $\mathrm{IIH}$ components xeroderma pigmentosum B and p62. J Biol Chem 1998; 273: 27794-27799.

36. Rigaut G, Shevchenko A, Rutz B, Wilm M, Mann M, Séraphin B. A generic protein purification method for protein complex characterization and proteome exploration. Nat Biotechnol 1999; 17: 1030-1032.

37. Rumpf C, Cipak L, Dudas A, Benko Z, Pozgajova M, Riedel CG et al. Casein kinase 1 is required for efficient removal of Rec8 during meiosis I. Cell Cycle 2010; 9: 2657-2662.

38. Rumpf C, Cipak L, Schleiffer A, Pidoux A, Mechtler K, Tolić-Nørrelykke IM et al. Lase microsurgery provides evidence for merotelic kinetochore attachments in fission yeast cells lacking Pcs1 or Clr4. Cell Cycle 2010; 9: 3997-4004.

39. Cipak L, Spirek M, Novatchkova M, Chen Z, Rumpf C, Lugmayr W et al. An improved strategy for tandem affinity purification-tagging of Schizosaccharomyces pombe genes. Proteomics 2009; 9: 4825-4828.
40. Gregan J, Riedel CG, Petronczki M, Cipak L, Rumpf C, Poser I et al. Tandem affinity purification of functional TAP-tagged proteins from human cells. Nat Protoc 2007; 2: $1145-1151$.

41. Ho L, Crabtree GR. Chromatin remodelling during development. Nature 2010; 463: 474-484.

42. Hong EJ, West AE, Greenberg ME. Transcriptional control of cognitive development. Curr Opin Neurobiol 2005; 15: 21-28.

43. Hsieh J, Gage FH. Chromatin remodeling in neural development and plasticity. Curr Opin Cell Biol 2005; 17: 664-671.

44. Goldberg AD, Allis CD, Bernstein E. Epigenetics: a landscape takes shape. Cell 2007; 128 : 635-638.

45. Wang W, Xue Y, Zhou S, Kuo A, Cairns BR, Crabtree GR. Diversity and specialization of mammalian SWI/SNF complexes. Genes Dev 1996; 10: 2117-2130.

46. Wu JI, Lessard J, Olave IA, Qiu Z, Ghosh A, Graef IA et al. Regulation of dendritic development by neuron-specific chromatin remodeling complexes. Neuron 2007; 56 : 94-108

47. Chatterjee S, Mizar P, Cassel R, Neidl R, Selvi BR, Mohankrishna DV et al. A novel activator of $\mathrm{CBP} / \mathrm{p} 300$ acetyltransferases promotes neurogenesis and extends memory duration in adult mice. J Neurosci 2013; 33: 10698-10712.

48. Laposa RR, Huang EJ, Cleaver JE. Increased apoptosis, p53 up-regulation, and cerebella neuronal degeneration in repair-deficient Cockayne syndrome mice. Proc Natl Acad Sci USA 2007; 104: 1389-1394.

49. Brace LE, Vose SC, Vargas DF, Zhao S, Wang XP, Mitchell JR. Lifespan extension by dietary intervention in a mouse model of Cockayne syndrome uncouples early postnatal development from segmental progeria. Aging Cell 2013; 12: 1144-1147.

50. Sacco R, Tamblyn L, Rajakulendran N, Bralha FN, Tropepe V, Laposa RR. Cockayne syndrome b maintains neural precursor function. DNA Repair (Amst) 2013; 12: 110-120.

51. Walton RM. Postnatal neurogenesis: of mice, men, and macaques. Vet Pathol 2012; 49: 155-165.

52. Yang Z, Ming GL, Song $H$. Postnatal neurogenesis in the human forebrain: from two migratory streams to dribbles. Cell Stem Cell 2011; 9: 385-386.

53. Feliciano DM, Bordey A. Newborn cortical neurons: only for neonates? Trends Neurosci 2013; 36: 51-61.

54. Robbins JH, Brumback RA, Mendiones M, Barrett SF, Carl JR, Cho S et al. Neurological disease in xeroderma pigmentosum. Documentation of a late onset type of the juvenile onset form. Brain 1991; 114: 1335-1361.

55. Przedborski S, Vila M, Jackson-Lewis V. Neurodegeneration: what is it and where are we? J Clin Invest 2003; 111: 3-10.

56. Guzy RD, Schumacker PT. Oxygen sensing by mitochondria at complex III: the paradox of increased reactive oxygen species during hypoxia. Exp Physiol 2006; 91: 807-819.

57. Aamann MD, Sorensen MM, Hvitby C, Berquist BR, Muftuoglu M, Tian J et al Cockayne syndrome group $B$ protein promotes mitochondrial DNA stability by supporting the DNA repair association with the mitochondrial membrane. FASEB J 2010; 24 2334-2346.

58. Scheibye-Knudsen M, Ramamoorthy M, Sykora P, Maynard S, Lin PC, Minor RK et al. Cockayne syndrome group $\mathrm{B}$ protein prevents the accumulation of damaged mitochondria by promoting mitochondrial autophagy. J Exp Med 2012; 209: 855-869.

59. Berquist BR, Canugovi C, Sykora P, Wilson DM, Bohr VA. Human Cockayne syndrome B protein reciprocally communicates with mitochondrial proteins and promotes transcriptional elongation. Nucleic Acids Res 2012; 40: 8392-8405.

(1) $(9)$ Cell Death and Disease is an open-access journal By ${ }^{\mathrm{NC}} \mathrm{ND}$ published by Nature Publishing Group. This work is licensed under a Creative Commons Attribution-NonCommercialNoDerivs 3.0 Unported License. The images or other third party material in this article are included in the article's Creative Commons license, unless indicated otherwise in the credit line; if the material is not included under the Creative Commons license, users will need to obtain permission from the license holder to reproduce the material. To view a copy of this license, visit http://creativecommons.org/licenses/ by-nc-nd/3.0/ 